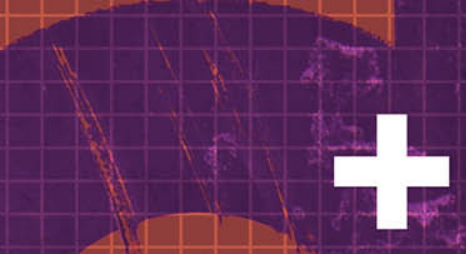




\title{
Desenvolvimento autônomo e crise estrutural do capitalismo no século XXI
}

\author{
Autonomous Development and Structural \\ Crisis of Capitalism in the $21^{\text {st }}$ Century
}

\author{
Humberto Machado Lima Junior*
}

\begin{abstract}
Resumo
Este artigo aborda como os princípios constitutivos do conceito de desenvolvimento autônomo de Hélio Jaguaribe oferecem respostas à crise estrutural do capitalismo global no século XXI. Essa crise émarcada pelo empoderamento do capital sobre o trabalho que repercute na privatização do capital e na estagnação da demanda. Diante desse processo político-econômico global, gerado pela austeridade neoliberal, o desenvolvimento autônomo aponta para políticas distributivas e de transformação produtiva das economias periféricas visando o reequilíbrio da divisão internacional do trabalho. Tal perspectiva aproxima as teses de Jaguaribe das propostas neokeynesianas para conter o avanço do neofascismo global no início do século XXI.
\end{abstract}

Palavras-chave: Desenvolvimento Autônomo Neoliberalismo - Neokeynesianismo - Capitalismo - Democracia.

\begin{abstract}
This article discusses how the constitutive principles of HélioJaguaribe's concept of autonomous development provide answers to the structural crisis of global capitalism in the 21st century. This crisis is marked by the empowerment of capital over labor that has an impact on the privatization of capital and the stagnation of demand. In the face of this global political-economic process, generated by neoliberal austerity, autonomous development points to distributive and productive transformation policies in peripheral economies aiming at rebalancing the international division of labor. This perspective brings Jaguaribe's theses closer to the neo-Keynesian proposals to contain the advance of global neo-fascism in the beginning of the $21^{\text {st }}$ century.
\end{abstract}

Keywords: Autonomous Development - Neoliberalism - Neokeynesianism - Capitalism - Democracy.

\footnotetext{
* Professor de SciencesPo-Paris - Printemps 2019. Pesquisador Visitante ITS-Rio. https://orcid.org/0000-0001-5846-0403.E-mail: humbertoplatao@bol.com.br
} 


\section{INTRODUÇÃO}

Um dos cânones da ciência política e da sociologia produzidas no Brasil, fundador e primeiro presidente do Iseb ${ }^{1}$ (principal centro difusor da ideologia nacional-desenvolvimentista), Hélio Jaguaribe deixou um legado teórico que se comunica não apenas com os anos 1950, mas, sobretudo, com o desenvolvimento global do século XXI. Em sua obra clássica $O$ Nacionalismo na Atualidade Brasileira (1958), Jaguaribe analisa como através do desenvolvimento autônomo seria possível a países periféricos regularem a entrada de capital externo de maneira a alterarem seu status na divisão internacional do trabalho. Essa mudança seria promovida pela intervenção de um Estado Keynesiano forte que suprimisse a sobre-representação na burocracia estatal dos segmentos sociais tradicionais comprometidos com a lógica exploratória dos países centrais.

A hipótese investigada nesse artigo é de que esse mecanismo de controle na administração pública local do clientelismo orientado de políticas econômicas internacionais dialoga com as respostas do Neokeynesianismo Global à crise estrutural do capitalismo no século XXI. Por meio de análise bibliográfica, esse artigo pretende mostrar como as teses sobre o desenvolvimento autônomo se inserem no debate sobre governança global no que tange a realização de acordos transnacionais que promovam políticas distributivas e de inclusão democrática para equilibrar a relação entre capital e trabalho e conter o avanço do neofascismo global (WOLF, 2019; PIKETTY, 2014; KRUGMAN, 2018).

$\mathrm{Na}$ sessão inicial abordaremos o papel do desenvolvimento autônomo para a transformação produtiva com equidade social, assim como, para o enfrentamento do cartorialimo ${ }^{2}$ exercido pelas elites tradicionais interessadas na manutenção da economia nacional em status periférico no sistemamundo. Na parte seguinte, trataremos dos efeitos da austeridade neoliberal em escala global sobre o aumento da assimetria entre centro e periferia, sobre o empoderamento do capital em relação ao trabalho, e por conseguinte, sobre a crise estrutural do capitalismo global no século XXI. Por fim, iremos analisar as contribuiçốes do Desenvolvimento Autônomo e do Neokeynesianismo Global para a crise do modelo de desenvolvimento global pósneoliberal.

Por Estado cartorial se entende, basicamente, um Estado caracterizado pelo fato de que as funções públicas, embora se apresentando como atividades orientadas para a prestação de determinados serviços à coletividade, ou seja, determinados "serviços públicos" são, na verdade, utilizadas, se não mesmo concebidas, para assegurar empregos e vantagens específicas a determinadas pessoas e grupos. O Estado cartorial é o resultado típico da política 
de clientela quando esta atinge amplas proporçôes e permeia o Estado em seu conjunto.” Acessível em: http://www.fgv.br/Cpdoc/Acervo/dicionarios/ verbete-tematico/estado-cartorial

\section{O DESENVOLVIMENTO AUTÔNOMO E A ASCENSÃO DAS ECO- NOMIAS PERIFÉRICAS NO CAPITALISMO GLOBAL}

O desenvolvimento autônomo de uma nação, segundo Hélio Jaguaribe, parte da capacidade dos seus setores progressistas, unidos em um pacto supraclassista, de modificar o modo de produção nacional, através de uma transformação tecnológica, tendo em vista o projeto histórico de seu povo. Essa transformação produtiva, à luz da tomada de consciência crítica da formação histórica da nação, requer uma reforma institucional que desvencilhe a burocracia estatal do aparelhamento reacionário por parte das elites tradicionais e permita ao Estado promover o desenvolvimento nos níveis político, econômico e ideológico (SOUZA \& SILVA, 2007). Está implícita nessa análise a relação de sustentação recíproca entre estrutura (modo produtivo) e superestrutura (ideologia e instituiçóes sociais e políticas), tal como se expressa na teoria marxista (JAGUARIBE, 2014).

Nesse quadro teórico, a subjugação epistêmica às matrizes eurocêntricas, que tornavam difusa a percepção popular sobre o processo histórico nacional, teria sido legada do período colonial para o republicano gerando uma ideologia nacional de raízes exógenas subalterna aos interesses dos países centrais do capitalismo. Essa subalternidade ideológica seria reproduzida pelas classes tradicionais vinculados ao modo de produção que mantém o país em condição periférica perante a divisão internacional do trabalho em que os países centrais apresentam um modo produtivo capital-intensivo, com concentração tecnológica, enquanto os países periféricos se voltam para a produção de commodities trabalho-intensiva (SOUZA \& SILVA, 2007).

A percepção de Jaguaribe sobre a divisão internacional do trabalho parte da sua leitura das teses elaboradas pelo economista Raúl Prebisch junto à CEPAL as quais estabeleciam um diálogo entre o keynesianismo e a teoria estruturalista. Do livro A teoria geral do emprego, do juro e da moeda Prebisch assumiu a premissa keynesiana de que a auto regulação do mercado não seria capaz de oferecer respostas aos problemas cíclicos do capitalismo no que tange ao desemprego estrutural e à distribuição e renda. A resolução desses casos precisaria da construção de um Estado forte que atuasse diretamente na economia de maneira a constante inovação tecnológica e a dinamização do mercado. Desse modo, o Estado seria capaz de controlar a 
competitividade do mercado, assim como o desemprego e a distribuição de renda e capital (MACHADO LIMA JUNIOR, 2013).

A partir dessa orientação keynesiana, Prebisch definiu seus conceitos de "ciclo-econômico" e "sistema centro-periferia". Por "ciclo-econômico" entende-se os impulsos constantes de expansão e contração da vida econômica em escala global. Tais impulsos seriam gerados nos países centrais (produtores de bens industrializados) e produziriam reflexos nos países periféricos (produtores de bens primários). Assim, a dicotomia centro-periferia seria o resultado histórico do modo como evoluiu o progresso técnico na economia global que repercutiu na diferenciação funcional complementar de estruturas produtivas no sistema econômico global. Por conseguinte, a divisão internacional do trabalho seria determinada segundo a distinção funcional entre centro e periferia na economia-mundo (MACHADO LIMA JUNIOR, 2013).

Jaguaribe complementa a teorização de Prebisch ao analisar os conflitos intrínsecos ao sistema político brasileiro que moldam a inserção da economia nacional na divisão internacional do trabalho. Segundo suas reflexôes, dois blocos teriam se polarizado na formação da nação brasileira em virtude da divergência sobre o posicionamento do país na economia-mundo. De um lado, o setor que o autor define como "atrasado" em virtude do seu vínculo com a manutenção da economia nacional em posição periférica. Nesse grupo estariam as oligarquias agrário-exportadoras, a burguesia mercantil, a classe média cartorial e o campesinato. De outro lado, o segmento "moderno" identificado com a transformação produtiva e a mudança de status da economia brasileira no sistema-mundo. A burguesia industrial, a classe média técnica e administrativa e o proletariado estariam nessa vertente. Jaguaribe via uma contradição no processo brasileiro de modernização na medida em que as instituiçôes democráticas liberais tinham o seu sentido subvertido pela ideologia e pelas práticas sociais e políticas legadas despotismo do período colonial. Seguindo essa lógica, os setores “atrasados” aparelhariam a burocracia estatal por meio de estratégias clientelistas de distribuição de benefícios em troca de apoio político e eleitoral (SOUZA \& SILVA, 2007) $\mathrm{O}$ autor destaca esse conflito no seguinte trecho de O Nacionalismo na Atualidade Brasileira:

O Estado brasileiro, desde a Colônia, tornou-se cartorial e assim persiste em nossos dias. Caracteriza-se o Estado cartorial por ser o instrumento de manutenção de uma estrutura econômico-social fundada numa economia primária de exportação e nos privilégios de classe a ela correlatos. Sua nota distintiva reside no fato de que o serviço público, em lugar de consistir no atendimento das necessidades coletivas, é um mecanismo de manipulação das clientelas eleitorais destinado a perpetuar os privilégios da classe dominante, proporcionando, sem a 
contrapartida da prestação de serviços efetivos e socialmente necessários, empregos e favores à clientela dos grupos dirigentes. (Jaguaribe, Hélio. O Nacionalimo na Atualidade Brasileira, pp 54-55)

Portanto, a construção de um projeto de desenvolvimento que atuasse na composição das importações e na diversificação das exportações de modo a equilibrar a balança comercial internacional dependeria da supressão do poder clientelista dos setores atrasados na máquina estatal e de um pacto entre as classes modernas entorno da ideologia do desenvolvimento autônomo. Para tanto, as classes "modernas" deveriam realizar uma reforma política institucional em resposta aos "pontos de estrangulamento" do desenvolvimento econômico resultantes da reprodução de práticas políticas herdadas do período colonial. Tais pontos de estrangulamento seriam referentes ao capital de investimento no setor produtivo e na infraestrutura para o desenvolvimento (SOUZA \& SILVA, 2007).

Em O Nacionalismo na Atualidade Brasileira (1958/2013), Jaguaribe argumenta sobre o papel positivo do capital estrangeiro para a solução dos referidos 'pontos de estrangulamento' do desenvolvimento nacional. Nesse sentido, o aporte do capital estrangeiro poderia proporcionar o aumento da capacidade de importação que iria repercutir no fortalecimento da indústria nacional e do mercado interno. Paradoxalmente, a entrada do capital externo estaria relacionada à proteção do sistema produtivo dos países centrais que teriam por objetivo a garantia de mercado para seus produtos, a exploração e controle das reservas naturais dos países periféricos - sob restrição de soberania nacional - e acesso a fatores de produção mais baratos (mão de obra e matéria prima (JAGUARIBE, 2013, p. 268). Perante esse paradoxo, um Estado Keynesiano Autônomo, comprometido com os setores progressistas da sociedade entorno da ideologia nacional-desenvolvimentista, poderia neutralizar os efeitos nocivos do capital externo e disciplinar o empresariado nacional para conter o efeito colonizador do financiamento externo (JAGUARIBE, 2013, p. 273)

No que tange à escassez de capital de investimento no setor produtivo, Jaguaribe ressalta as características manchesterianas do empresariado brasileiro dos anos 1950 que dispunha apenas do próprio capital e fundia as funções de investidor e empresário (JAGUARIBE, 2013, p. 273) A limitação ao próprio capital torna esse modelo de empresário incapaz de fazer os investimentos necessários para que o crescimento produtivo e a dilatação do mercado permitam que a capacidade de poupança do conjunto da população seja superior à capacidade de poupança e investimento da classe capitalista. Por consequência, é obstruída a transição do capitalismo manchesteriano para o capitalismo social no qual a base do sistema produtivo se move da 
poupança dos proprietários de capital para a progressiva acumulação de capital social. O duplo papel de empresário e financiador assumido pelo burguês manchesteriano tradicional brasileiro o induz a práticas de alta lucratividade por unidade de produto/serviço e de elevada concentração de capital. Como resultado, essa burguesia manchesteriana periférica atada a um estágio incipiente da modernidade tende a se afastar dos setores econômicos de base que são destinados ao capital estrangeiro ou ao Estado (JAGUARIBE, 2013, p. 274). Por outro lado, a burguesia tradicional se beneficia das práticas cartorias exercidas pelas elites tradicionais na burocracia estatal referentes à privatização dos lucros e socialização das perdas.

O conceito de socialização das perdas foi elaborado por Celso Furtado tendo como objeto de análise o período de monocultura cafeeira no Brasil altamente dependente do mercado externo. Durante esse período, em cenários de crise econômica internacional, o governo brasileiro promovia a desvalorização da moeda local perante a libra (adotada como padrão ouro) para evitar a queda do preço do café na moeda britânica. Desse modo, os lucros do setor exportador eram garantidos e os reflexos da crise nos países centrais eram transferidos para o mercado interno através do encarecimento de produtos importados (ALVARENGA JUNIOR \& MANSOR DE MATTOS, 2015). Furtado argumentava que essa transferência de perdas tinha efeito regressivo sobre a distribuição de renda e afetava de modo mais drástico as classes assalariadas em virtude da diferenciação de consumo de produtos importados por classe social:

Bastaria atentar na composição das importações brasileiras no fim do século passado e no começo deste, $50 \%$ das quais eram constituídas por alimentos e tecido, para dar-se conta do vulto dessa transferência. Durante a depressão, as importações que se contraíam menos - dada a baixa elasticidade-renda de sua procura eram aquelas de produtos essenciais utilizados pela grande massa consumidora. Os produtos de consumo de importação exclusiva das classes não assalariadas apresentavam elevada elasticidade-renda, dado seu caráter de não essencialidade. (Furtado, 1959/1967, p. 165)

Sob esse aspecto, a política tributária vinculada ao comércio exterior concorria para a socialização de perdas e crescimento das desigualdades sociais em cenários de crise internacional. Tal ocorria na medida em que o imposto sobre importação - cobrado em moeda nacional a uma taxa de câmbio fixa sobre o valor do produto - se mantinha estável quando havia alta de preços de produtos importados em virtude de crises internacionais. Assim, os consumidores nacionais de mercadorias de valores mais elevados eram menos onerados pela política tributária do que as classes que consumiam itens de menor custo (ALVARENGA JUNIOR \& MANSOR DE MATTOS, 2015). 
O modo produtivo brasileiro no século XXI adquire um status semiperiférico (permanecendo periferia do norte global e sendo centro perante países menos industrializados) Entretanto, a burguesia nacional preserva algumas características manchesterianas e mantém práticas de socialização de perdas e privatização de lucros promovidas por meio de açóes clientelistas e cartoriais das elites tradicionais nas instituiçóes políticas representativas. A política tributária adotada no Brasil desde o nacional-desenvolvimentismo dos anos 1950 até o pós-neodesenvolvimentismo desempenha um papel central na socialização deperdas e privatização de lucros na economia brasileira, bem como, no agravamento das desigualdades sociais. Ao invés de atenuar a desigualdade produzida pelas fontes primárias de geração de renda, o sistema tributário brasileiro tem assumido um efeito regressivo através do qual a participação dos tributos sobre a renda e o patrimônio dos indivíduos cresce em proporção inversa a estes. Assim, paga imposto relativamente mais alto quem possui renda menor (MANSOR DE MATTOS, 2017).

O modelo de desenvolvimento nacional posterior ao Golpe Militar de 1964 implementou uma política tributária que sobretaxou os salários dos trabalhadores ao mesmo tempo que ofereceu isençóes fiscais ao empresariado. Esta reforma tributária subsidiou a elevação do consumo das classes de rendas altas e médias-altas que proporcionou a acumulação de capital no período e concorreu para a sustentação do regime militar. Nos anos neodesenvolvimentistas, entre 2004 e 2013, apesar dos avanços em políticas distributivas e redução de desigualdades (Benefício de Prestação Continuada, Bolsa Família, etc.) houve uma transferência progressiva de ganhos da renda familiar para o setor financeiro no processo de mercantilização dos serviços públicos (MANSOR DE MATTOS, 2017). Assim, o pacto supraclassita (fundamental para a difusão da ideologia desenvolvimentista que promoveria a mudança de status do Brasil no sistema-mundo), vem sendo sistematicamente sabotado pelo cartorialismo das elites tradicionais até a crise do neodesenvolvimentismo.

Diante do cartorialismo da elite tradicional vinculada geopoliticamente às políticas protecionistas de países centrais que visam manter o país em condição periférica e impedir a socialização do capital, a perspectiva de desenvolvimento autônomo permaneceria um vetor da transformação do modo produtivo brasileiro na divisão internacional do trabalho. Nesse sentido, um Estado interventor forte, com instituiçóes representativas estruturadas de modo a coibir a sobre-representação cartorial das elites tradicionais e a acolher setores moderno da sociedade, poderia promover a mudança de status da economia nacional no sistema-mundo. 
Veremos adiante como o modelo de desenvolvimento autônomo proposto por Jaguaribe apresenta respostas à crise estrutural do capitalismo global no século XXI - marcada pela elevação progressiva da pobreza e da concentração de capital, que conduz à estagnação da demanda e à crise de legitimidade democrática. $\mathrm{O}$ avanço global da austeridade neoliberal concomitante ao crescimento de grupos políticos neofascistas - que resultam em uma política externa protecionista das economias do norte em relação ao sul global - constituem uma oposição ao modelo de desenvolvimento sustentável, distributivo e inclusivo defendido pelos atores de governança global. Nesse cenário, o modelo de desenvolvimento autônomo dos Estados - sobretudo, do sul global - oferece condiçôes para a realização de acordos multilaterais que horizontalizem a globalização e promovam as mudanças no modelo de desenvolvimento global em resposta aos seus desafios estruturais.

\section{OS IMPACTOS DA AUSTERIDADE NEOLIBERAL SOBRE A CRISE ESTRUTURAL DO CAPITALISMO GLOBAL NO SÉCULO XXI}

As teses sobre a consolidação do liberalismo econômico como única e definitiva alternativa para o sistema econômico global se projetaram a partir da dissolução do regime socialista. O slogan There is no alternative, da primeira ministra britânica Margareth Thatcher, e a Teoria do Fim da História, do filósofo e economista Francis Fukuyama, sintetizam as referidas teses que foram assimiladas pela 'serie de governos de orientação neoliberal que conquistaram o poder na Europa e nos EUA ao longo dos anos 1980 (MACHADO LIMA JUNOR, 2020).

A idéia defendida por Thatcher e Fukuyama de que a complementaridade entre liberalismo econômico e democracia liberal constituiriam um regime político-econômico que se tornaria global foi inspirada no pensamento de Herbert Spencer. Em Social Statics (Spencer,1851/2020), a negação a todas as restriçốes comerciais baseava-se na defesa moral e prática dos direitos individuais entendidos como 'liberdades comuns". Desse modo, o slogan da premier britânica exprimia a noção de que o livre mercado seria a forma mais eficaz de construir a riqueza, distribuir os serviços e expandir a economia das sociedades a partir da fase pós industrial do capitalismo. Em diálogo com essa perspectiva, Fukuyama (1982) fundamenta sua teoria sobre o fim da história no argumento filosófico de Hegel, pela interpretação de Alexandre Kojève (2002), de que a ascensão do liberalismo e da igualdade jurídica levariam a humanidade a atingir o equilíbrio entre seus antagonismos acarretando o fim dos processos históricos de mudança, o que significaria o fim da história. (Anderson, 1992). 
Tanto para Hegel quanto para Marx a evolução das sociedades humanas não era ilimitada. Mas terminaria quando a humanidade alcançasse uma forma de sociedade que pudesse satisfazer suas aspirações mais profundas e fundamentais. Desse modo, os dois autores previam o 'fim da História'. Para Hegel seria o estado liberal, enquanto para Marx seria a sociedade comunista. (FUKUYAMA, 1992, p. 12)

Com base nessa premissa hegeliana, Fukuyama defende que a democracia liberal seria o estágio evolutivo mais perfeito da humanidade no qual o fascismo e o socialismo (por ele definidos como experiências totalitárias) teriam sido suplantados Assim, a luta de classes estaria resolvida por meio de um regime político que distribuísse de maneira justa o acesso aos direitos sociais e as oportunidades de sucesso material. (MACHADO LIMA JUNIOR, 2020)

Dos diferentes tipos de regimes surgidos no curso da história da humanidade, desde monarquias e aristocracias até as teocracias religiosas e as ditaduras fascistas e comunistas deste século, a única forma de governo que sobreviveu intacta até o fim do século XX foi a democracia liberal. (FUKUYAMA, 1992, p. 80).

Perry Anderson analisa que embora tenha adquirido maior projeção a partir da decadência do socialismo real, o neoliberalismo surgiu logo no início da Guerra Fria como uma reação ao intervencionismo estatal e à construção do Estado de Bem Estar na Europa do Pós Guerra. A obra de origem do pensamento neoliberal, em distinção ao liberalismo clássico, é $O$ Caminho da Servidão, de Friedrich Hayek (1944) a qual sustenta que tanto o socialismo quanto o nazismo e o fascismo, assim como o Estado previdenciário, conduziriam ao cerceamento da liberdade dos indivíduos e, por conseguinte, ao totalitarismo. Sob essa ótica, o planejamento estatal e o Estado Keynesiano teriam um componente totalitário na medida em que o controle econômico que propóem tenderia a paralisar as forças dinâmicas da sociedade impedindo a formação de uma sociedade livre. Nas palavras de Hayek, " a ascensão do nazismo e do fascismo não foi uma reação contra as tendências socialistas do período precedente, mas o resultado necessário dessas mesmas tendências" (Hayek, 1944/2010).

Entorno das ideias de Hayek, reuniram-se intelectuais que se opunham tanto ao Welfare State Europeu quanto aos programas assistenciais do capitalismo keynesiano implementado pelo presidente Roosevelt nos EUA. Entre tais intelectuais podemos destacar Milton Friedman, Karl Popper, Walter Lipman e Michael Polanyi. (ANDERSON, 1995). Contudo, a repercussão de suas críticas antisocialistas e antikeynesianas foi reprimida pelo avanço do capitalismo internacional de forma associada à consolidação democrática e ao Estado de Bem Estar durante as décadas de 1950 e 1960 (ANDERSON, 1995). 
A expansão concomitante do keynesianismo e do fordismo/taylorismo em escala global, entre as décadas de 1940 e 1980, promoveu o empoderamento do trabalho sobre o capital através da cooperação entre sindicatos, setores produtivos e o Estado (MOTA, 2013). Contudo, a diversificação da demanda, gerada pelo modelo fordista-taylorista (que marcou o modo de produção capitalista durante os anos keynesianos) levou o capitalismo global a uma crise estrutural mediante a incapacidade do modo de produção capitalista em atender à pluralidade da demanda por ele próprio gerada. Essa crise estrutural, ao lado da derrocada do socialismo real, criou oportunidades políticas de expansão do discurso neoliberal a partir dos anos 1980 (MACHADO LIMA JUNIOR, 2020)

A crise financeira de 2008, nos EUA, que teve reflexos na crise financeira na Europa em 2010, deu novo impulso à austeridade neoliberal. A dificuldade em retomar o crescimento produtivo, motivou a criação de inovações financeiras como forma de estimular o consumo sem aumentar a produção. Tais inovações eram baseadas em linhas de cartão de crédito, hipotecas e tipos diversos de flexibilização de endividamento. (MOTA, 2013) Essas reformas configuraram um tipo de capitalismo que tinha como fonte principal de lucro e mais valia o crédito em si mesmo ao mesmo passo em que era marcado por estagnação salarial e precarização das relações de trabalho. Essa nova fase do capitalismo foi denominada pelo sociólogo Zygmunt Bauman de "capitalismo parasitário" (BAUMAN, 2010). Nessa fase do capitalismo, o endividamento permanente e a constante transferência de parte da renda dos trabalhadores para o sistema bancário, sob a forma de juros bancários, são elementos fundamentais para a manutenção da capacidade de auto-reprodução do sistema (MOTA, 2013).

Nos Estados Unidos, o endividamento médio das famílias cresceu algo em torno de $22 \%$ nos últimos oito anos - tempos de uma prosperidade que parecia não ter precedente. A soma total das aquisições com cartôes de crédito não ressarcidas cresceu $15 \%$. E a dívida, talvez ainda mais perigosa, dos estudantes universitários, futura elite política, econômica e espiritual da nação, dobrou de tamanho. O adestramento para a arte de "viver em dívida" e de forma permanente foi incluído nos currículos escolares nacionais. A Grã-Bretanha também chegou a situação bem semelhante. Em agosto de 2008, a inadimplência dos consumidores superou o total do Produto Interno Bruto da GräBretanha. As famílias britânicas têm dívidas num valor superior a tudo o que suas fábricas, fazendas e escritórios produzem (BAUMAN, 2010, p. 20).

A precarização das relaçóes de produção que marca o capitalismo parasitário - na definição de Bauman - ou capitalismo financeirizado - termo utilizado por Harvey (2011) para designar o mesmo fenômeno - é fruto 
da flexibilização econômica promovida pelo neoliberalismo e da destruição parcial do Estado de Bem Estar.

Do ponto de vista do regime democrático, as crises financeiras de 2008 e 2010 impactaram na crise de legitimidade dos partidos de esquerda (MOTA, 2013). Tal ocorreu porque tanto o governo democrata de Barack Obama, nos EUA, quanto os partidos socialistas e sociais democratas europeus, procuraram solucionar a crise através de políticas públicas voltadas para sanear os bancos em detrimento das necessidades do conjunto da população.

A perda da referência dos partidos socialistas e sociais democratas como antítese ao neoliberalismo leva a polarização do debate político entre extrema direita e extrema esquerda no que tange à perspectiva de auto-representação do povo. (GERBAUDO, 2017).

O crescimento contínuo da concentração de capital e, por conseguinte, das desigualdades sociais, no capitalismo mundial durante os dois últimos séculos se fundamenta na superação da taxa de retorno sobre o capital em relação à taxa de crescimento da renda (PIKETTY, 2014). Esse fenômeno de privatização de capital em escala global configura uma contradição na medida em que, de acordo com o pensamento econômico neoclássico, a auto-reprodução e expansão do sistema dependem do crescimento da renda. (HARVEY, 2014) Contudo, o recrudescimento das desigualdades a partir da expansão da austeridade neoliberal, iniciada nos anos 1980, tem bases no desequilíbrio de poder entre capital e trabalho. Sob a ótica marxista, a organização e a ação coletiva da classe trabalhadora (dentro de um sistema democrático liberal em que as instituiçôes representativas sejam reconhecidas como legítimas) constituem uma oposição às estratégias, tanto do Estado quanto do mercado, que impeçam a socialização do capital. De modo contrário, os governos neoliberais implementaram políticas de redução de custos de produção através do aumento do desemprego (para ampliação de exército industrial de reserva), da perda de direitos trabalhistas e da redução salarial. Essas medidas, declaradas anti-inflacionárias, enfraqueceram politicamente a classe trabalhadora e, por conseguinte, facilitaram a sobre-representação política dos donos do capital (Harvey, 2014).

Com o objetivo de elevação da privatização dos lucros sem antagonismos de classe, reduzindo empregos e rebaixando salários, o neoliberalismo prejudica a médio e longo prazos a possibilidade de auto reprodução e ampliação do crescimento econômico porque restringe a capacidade de consumo do mercado. A premissa de que a escassez de demanda efetiva estaria na base da grande depressão econômica da década de 1930 inspirou a expansão das políticas keynesianas, entre o fim da Segunda Guerra Mundial e os anos 1980, 
marcadas pela elevação da renda direta (salários) e indireta (Estado de Bem Estar Social), estabilidade democrática e empoderamento político da classe trabalhadora. Esse conjunto de políticas resultou na redução das desigualdades sociais e na retomada do crescimento produtivo tendo como apoio financeiro a tributação progressiva conforme a renda (WOLF, 2019) Com o fim do socialismo real e a ascensão globalização neoliberal houve a reformulação da política tributária, que tornou-se regressiva sem se traduzir em crescimento produtivo, bem como, a perda de legitimidade das democracias liberais e o crescimento da pobreza em escala global. Comparados o período keynesiano e o neoliberal, podemos observar que entre 1948 e 1973, a renda familiar média real nos Estados Unidos crescia a 3\% ao ano. Durante esse período, havia $96 \%$ de chance de que um indivíduo tivesse uma renda superior a de seus pais. A partir de 1973, a média de crescimento da renda familiar passou a crescer a $0,4 \%$ ao ano. Nessa nova realidade, $28 \%$ dos trabalhadores passaram a ter a renda inferior a de seus pais (WOLF, 2019). A análise comparativa destes processos político-econômicos indica para a centralidade da taxação progressiva e da tributação da riqueza global para a regulação da patrimonialização do capitalismo global, ou, nos termos de Celso Furtado, privatização de lucros e socialização de perdas em escala global.

O economista Paul Kurgman (2018) analisa como as políticas de baixa tributação e auto regulação do mercado do Estado Mínimo Neoliberal nos EUA, desde os anos 1980, têm se refletido em um crescimento econômico pífio e na redução da renda da classe trabalhadora. O autor destaca a importância da regulação estatal sobre o mercado para conter a elevação progressiva da concentração de capital provocada pela formação do monopsônio. De modo inverso ao monopólio, no qual apenas um produtor/vendedor controla o mercado, o monopsônio ocorre quando uma única empresa compradora (monopsolista) detém o mercado. Essa prática, além de controlar os preços, vem reduzindo salários e contratação de trabalhadores. Como solução para as contradições neoliberais, Krugman indica o empoderamento do trabalho (sindicatos, associações, fóruns, etc) sobre o capital tendo por base a ação de um Estado Keynesiano que regule as relaçôes trabalhistas e garanta os direitos de organização e ação política da classe trabalhadora.

A retração da socialização de capital causada pelas práticas neoliberais de eliminação da concorrência no mercado, fraco crescimento produtivo e tributação regressiva tem repercutido sobre a crise de legitimidade das democracias liberais no início do século XXI. A falta de regulação estatal sobre fusões e práticas anticompetitivas, assim como, sobre meio ambiente e relaçóes trabalhistas fomenta o descrédito dos trabalhadores e dos cidadãos comuns 
quanto ao sistema representativo por verem seus interesses serem sub-representados perante o lobby das corporações econômicas (Wolf, 2019).

As reformas que caracterizam o neoliberalismo - privatização de empresas públicas, flexibilização das relações produtivas, redução salarial, austeridade fiscal, tributação regressiva, etc. - têm sido realizadas em países europeus desde os anos 1980 tanto por governos de direita quanto de esquerda. Diante dessa realidade, o cidadão comum encontra dificuldade em diferenciar governos de esquerda e direita, no que tange às políticas econômicas, na medida em que o projeto neoliberal vem se perpetuando acima das divergências partidárias. Nesse contexto, o sistema representativo se configura como uma instância inacessível aos interesses populares aparelhada por uma elite que governa para si própria (MOUNK, 2018). O sistema democrático, como um todo, enfrenta uma crise de legitimidade que não se limita às instituições representativas, mas se estende a todo o repertório de açóes coletivas correspondente à democracia liberal. Desse modo, caem em descrédito popular os partidos políticos, as associaçôes de moradores, os diretórios estudantis, os grupos de minorias e os diversos coletivos. Por conseguinte, cresce a ideia no conjunto da população de que é necessário dissolver as instituiçóes democráticas e substituí-las pela auto-representação do povo, seja através de um indivíduo que se apresente como o líder carismático ou através da própria massa popular que se auto-configure como uma liderança carismática. Essa ideia de auto representação insufla tanto movimentos de extrema direita - de orientação ultranacionalista e neofascista - quanto movimentos de extrema esquerda - de perspectiva emancipatória, autonomista e neoanarquista - que confrontam o sistema democrático liberal por lados opostos. (MACHADO LIMA JUNIOR, 2020)

Diante da ascensão de governos de extrema direita com contornos fascistas ao redor do globo no início do século XXI, sem precedentes desde os anos 1930, o sociólogo William Robinson (2012) analisa a aliança entre o Estado e o capital entorno do projeto fascista. Nessa aliança, a elevação de concentração de capital, por meio de tributação regressiva e redução de empregos e salários (que leva a uma crise estrutural por estagnação do consumo), é exercida com o cerceamento do Estado Democrático de Direito e repressão política estatal. Enquanto no século XX a coligação fascista era entre Estado e capital nacional, no século XXI tornou-se entre poder público local e o capital transnacional - o que proporciona uma sobre-acumulação global de capital para além dos limites dos Estados Nacionais, dá uma propensão global ao projeto fascista e conduz a uma segunda da crise estrutural da demanda. Sob outro aspecto, o projeto fascista tem maior força de 
implementação no século XXI do que nos anos 1930 em virtude do enfraquecimento dos sindicatos, associações de trabalhadores e da ideologia socialista. (ROBINSON, 2012)

Alguns dos princípios clássicos do fascismo se mantêm na feição com que esse regime se mostra no século XXI. Entre os quais: a ideia de unidade nacional acima das individualidades e diferenças sociais; a auto-representação popular (sob a liderança carismática) em detrimento das instituições democráticas; a mobilização emocional das massas pela construção social do ódio; o autoritarismo; e o belicismo. Entretanto, as novas formas de controle social e dominação ideológica através das mídias digitais tornam difusas as fronteiras do autoritarismo e geram oportunidades para uma forma de fascismo constitucional (com instituições representativas formais, partidos políticos e eleiçôes) sob o controle do capital global e seus representantes (ROBINSON, 2012).

Nessa sessão, pretendemos fazer uma análise do processo político-econômico marcado pelo neoliberalismo e seus reflexos sobre a assimetria da divisão interncaional do trabalho, bem como sobre o empoderamento do capital perante o trabalho, a estagnação da demanda e a privatização do capital em escala global. Veremos a seguir, que respostas o modelo de desenvolvimento autônomo tem a oferecer à crise de legitimidade das democracias liberais e aos problemas estruturais do modelo de desenvolvimento global.

\section{INTERFACES ENTRE O DESENVOLVIMENTO AUTÔNOMO E O NEOKEYNESIANISMO GLOBAL EM PROL DO DESEN- VOLVIMENTO}

Diante da nova crise da demanda e da ascensão do neofascismo global, atores econômicos globais de orientação reformista - como George Soros, Joseph Stiglitz, Jeffrey Sachs e representantes políticos que se distanciam do pensamento econômico neoclássico - propóem uma regulação global dos mercados financeiros (ROBINSON, 2012). Além disso, sugerem intervençôes estatais, coordenadas em escala global, de transição da acumulação de capital do setor especulativo para o setor produtivo. Esses agentes defendem o Neokeynesianismo Global e compartilham a perspectiva distributiva através de uma tributação progressiva sobre as grandes fortunas em escala global análogas às análises de Wolf, Piketty, Krugman, e Harvey.

Tal como no keynesianismo que sucedeu à crise mundial da década de 1930, o Neokeynesianismo Global reconhece a complementaridade entre liberalismo e democracia e propóe, nesse sentido, que o fortalecimento 
do Estado Nacional passe pela legitimação da sua governança. Portanto, a administração pública deve promover a ampliação da participação das bases populares nos processos deliberativos e consultivos. Assim, a ameaça à estabilidade das instituições democráticas impulsionada pela ideia neofascista de auto-representação popular seria contida pelo reequilíbrio da relação entre capital e trabalho sob o controle do Estado Neokeynesiano Global.

A agenda de um modelo de desenvolvimento global distributivo (por meio de tributação progressiva e equilíbrio entre trabalho e capital), sustentável e democrático é assumida por instituições de governança global (como a ONU, OCDE, o Tribunal Penal Internacional, etc.) na organização de acordos transnacionais em resposta à crise estrutural do capitalismo no século XXI. Entretanto, a capacidade política desses atores enfrenta obstáculos causados pelo avanço da aliança entre neofascismo e neoliberalismo no sistema representativo das democracias ocidentais. Governos ultra-nacionalistas do norte global tendem a se opor ao multilateralismo trazido pela governança global e defendem acordos unilaterais que protejam o status de centralidade de suas economias no sistema mundo. Esses acordos unilaterais, que mantém as economias do sul global em condição periférica, são viabilizados a nível local através de práticas cartoriais na burocracia estatal exercidas pelas elites tradicionais ligadas ideológica e financeiramente ao protecionismo do norte global - um processo de globalização neofascista que se opóe ao Neokeynesianismo Global (ROBINSON, 2012).

Diante do antagonismo entre esses modelos de globalização, os elementos constitutivos da noção de desenvolvimento autônomo de Hélio Jaguaribe têm respostas a oferecer à crise estrutural do capitalismo no século XXI, bem como, à mudança de status das economias do sul global na divisão internacional do trabalho. Entre tais respostas, indica a centralidade de um Estado Keynesiano forte para articular um pacto supraclassista entre os setores modernizadores da sociedade de modo a definir uma ideologia desenvolvimentista e a suprimir o clientelismo das elites tradicionais - e, por conseguinte, coibir a interposição a nível local do neofascismo global.

$\mathrm{Na}$ visão de Jaguaribe, a mudança do modo produtivo periférico seria induzida pelo planejamento do Estado Autônomo através da entrada de capital externo de maneira a fortalecer o mercado interno e alterar a inserção do país na divisão internacional do trabalho. Nesse sentido, na geopolítica do início do século XXI, o modelo de desenvolvimento autônomo seria fundamental para garantir a capacidade política deliberativa de socialização de capital estabelecidas pelos Atores de Governança Global no que se refere à tributação progressiva em escala global e equilíbrio político entre capital e trabalho. O que tornaria esse modelo tão central para as deliberações 
distributivas em escala global seria o seu potencial político de enfrentamento do neofascismo global.

Nessa conjuntura global, assim como o equilíbrio entre capital e trabalho seria central para conter o avanço do neofascismo, o equilíbrio entre local e global (com o fortalecimento das instituiçôes democráticas dos Estados Nacionais) seria fundamental para a governança global em prol do neokeynesianismo global - de modo análogo à descrição de Otávio Ianni sobre as teorias da globalização (IANNI, 1996).

No que tange à complementaridade entre liberalismo econômico e democracia, o princípio de transformação produtiva com equidade social, incorporado à noção de desenvolvimento autônomo por Hélio Jaguaribe, traz uma sólida contribuição à resposta do neokeynesianismo global para a crise das democracias liberais. Por esse princípio, a distribuição de bens e serviços públicos, acrescida do aumento da renda do conjunto dos trabalhadores, seria uma pré-condição para a substituição de importaçôes através da consolidação da capacidade de auto reprodução das atividades econômicas, bem como, para a estabilização do sistema democrático. Essa visão de complementaridade entre desenvolvimento econômico, aperfeiçoamento do sistema democrático e mecanismos distributivos foi legada por Hélio Jaguaribe (e os intelectuais do Iseb) à definição do neodesenvolvimentismo brasileiro e incorporada às estratégias de inovação em administração pública na Europa no início do século XXI (MACHADO LIMA JUNIOR, 2020). Um dos principais alicerces do modelo neodesenvolvimentista consistia na ampliação das instituiçóes participativas como forma de aperfeiçoar o sistema representativo e conferir maior legitimidade às políticas de Estado. Desse modo, o sistema democrático brasileiro estaria baseado na interação recíproca entre o sistema representativo, o sistema participativo e o controle das burocracias (MACHADO LIMA JUNIOR 2015).

Diante do processo de redução da participação dos eleitores e da perda da confiança da população nas instituiçóes públicas, que se agravou na Europa pelos impactos sociais e políticos do avanço da austeridade neoliberal, houve uma apropriação das propostas participativas neodesenvolvimentistas por parte dos governos europeus no nível das administraçóes regionais (MACHADO LIMA JUNIOR, 2020). Importantes centros urbanos - Paris, Londres, Berlim, Milão, etc. - inovaram suas estruturas burocráticas por meio de mecanismos participativos inspirados no neodesenvolvimentismo brasileiro - sobretudo na experiência do orçamento participativo (SINTOMER, HERZBERG \& ROCKE, 2012).

Através do Orçamento Participativo os cidadãos comuns podem participar da administração pública no que se refere à distribuição dos fundos 
públicos. A estrutura de funcionamento do Orçamento Participativo adotada nos governos regionais europeus representa uma evolução em mecanismos de participação democrática institucional no que tange à digitalização dos canais participativos. Essa inovação tecnológica permite que o conjunto da população colabore de modo on-line com a gestão e aplicação dos recursos públicos - através de chatbots, pautas digitais e transmissóes on-line ao vivo das plenárias em mídias digitais - de modo conciliado com atividades presenciais (MACHADO LIMA JUNIOR, 2020). Em 2012, foram registradas cerca de quatrocentas plataformas e ferramentas digitais adotadas em cidades europeias na Europa por incentivo de governos e órgãos públicos (SINTOMER, HERZBERG \& ROCKE, 2012).

A ampliação da inserção dos cidadãos comuns nos processos deliberativos de políticas de Estado através de instituições participativas desconstrói a ideia de que as democracias liberais formam elites que governam para si próprias e, nesse sentido, contribui para a restituição da legitimidade do sistema democrático. Sob outro aspecto, a participação democrática institucional tem o efeito de contenção do neofascismo na medida em que esvazia a perspectiva auto representação popular e fortalece as instituições políticas.

\section{CONSIDERAÇÕES FINAIS}

O Neokeynesisanismo Global demonstra que a proposta neoliberal de flexibilização das relaçốes de trabalho como forma de dinamizar a economia leva o capitalismo global a uma nova crise da demanda. Como antítese, indica o empoderamento do trabalho sobre o capital como meio de estabelecer um equilíbrio democrático que contenha o avanço do neofascismo global e permita aos Estados Nacionais, interativos em uma governança global, fazer as reformas distributivas necessárias a solucionar a crise estrutural do capitalismo global. Os princípios constitutivos do desenvolvimento autônomo são fundamentais para essa inversão na relação entre capital e trabalho porque enfrenta os mecanismos locais da austeridade neoliberal em escala global. Como resposta à sedução das massas populares ao neofascismo global, o desenvolvimento autônomo propóe a participação democrática institucional e a conexão entre democracia direta e sistema representativo. A perda de legitimidade das democracias liberais provocada pela sobre representação neoliberal foi estendida ao repertório de ação coletiva da democracia. O desenvolvimento autônomo resgata a centralidade das formas desse repertório - os sindicatos, os partidos políticos, as associações de moradores, os grêmios e diretórios estudantis, etc.- para a reforma e auto-reprodução do desenvolvimento global. 


\begin{abstract}
Notas
'O ISEB (Instituto Superior de Estudos Brasileiro) foi criado em 1955 como órgão do Ministério da Educaçãoe Cultura. O grupo de intelectuais que o criou tinha como objetivos o estudo, o ensino ea divulgação das ciências sociais, cujos dados e categorias seriam aplicados à análise e à compreensão crítica da realidade brasileira e deveriam permitir o incentivo e a promoção do desenvolvimento nacional.' Acessível em: https://cpdoc.fgv.br/producao/dossies/JK/artigos/Economia/ISEB.

2 "Expressão cunhada e conceito desenvolvido por Hélio Jaguaribe em seu trabalho "Política ideológica e política de clientela", publicado no Jornal do Comércio de 14/5/1950 e em Digesto Econômico, São Paulo, 6 (68): 41-62, julho.
\end{abstract}

\section{Referências}

AFTER PARIS. Inequality, Fair Shares, and the Climate Change Emergency. Civil Society Equity Review. December, 2018.

ALVARENGA JUNIOR, $M$; MANSOR DE MATTOS, F. A. O conceito de socialização de perdas e seu papel na discussão da questão distributiva na obra Formação Econômica do Brasil, de Celso Furtado. Cadernos do Desenvolvimento. Rio de Janeiro. v. 15, n. 17, pp. 11-25. 2015.

ANDERSON, P. "Balanço do Neoliberalismo". In SADER, Emir \& GENTILLY, Pablo (orgs) Pós Neoliberalismo: as políticas sociais e o Estado democrático. Rio de Janeiro: Paz e Terra, 1995.

BAUMAN, Z.. Capitalismo Parasitário. Rio de Janeiro: Ed. Zahar, 2010.

BOSCHI, R.. Periphery and Semi-periphery. Ed. Routledge. (2012). New York.

FUKUYAMA, F. The End of History and the Last Man. New York: Free Press, 2006

FURTADO, C.. Formação Econômica do Brasil. Cia Editora Nacional: São Paulo, 1959/1967.

GERBAUDO, P. The Mask and the Flag. Oxford University Press, 2017.

GRAEBER, D. The New Anarchists. New Left Review. 13. January-February, 2002.

HARVEY, D. A Brief History of Neoliberalism. Oxford: Oxford University Press, 2005.

HARVEY, D. Afterthoughts on Piketty`s Capital. Acessível em: http://davidharvey. org/2014/05/afterthoughts-pikettys-capital/
HARVEY, D. O enigma do capital: e as crises do capitalismo. São Paulo: Boitempo, 2011.

HAYEK, F. A. O Caminho da Servidão. São Paulo: Instituto Ludwig von Mises Brasil, 2010.

IANNI, O. Teorias da Globalização. Rio de Janeiro: Ed. Civilização Brasileira, 1996.

JAGUARIBE, H. "ISEB - Um breve depoimento e uma reapreciação crítica". Cadernos do Desenvolvimento, v. 9, n. 14, pp.231 260. Jan-Jun. 2014.

JAGUARIBE, H. O Nacionalismo na Realidade Brasileira. Brasília: Funag, 2013.

KOJÉVE, A. Introdução à leitura de Hegel. Trad. Estela dos Santos Abreu. Rio de Janeiro: Contraponto/EDUERJ, 2002.

KRUGMAN, P. Capitalism, Socialism and Unfreedom. New York Times. Aug. 26, 2018

LACLAU, E. A Razão Populista. São Paulo: Ed. Três Estrelas, 2013.

MACHADO LIMA JUNIOR, H. A Ressignificação da Dependência no Novo-Desenvolvimentismo Brasileiro. Ponto de Vista, n. 9, Setembro, 2013.

MACHADO LIMA JUNIOR, H. (2020). "As Contribuições do Ipea para a legitimidade da Democracia Liberal". In: Titonelli Nunes, B. \& Cardoso Junior, J. Celso; Org.). Ipea diante do espelho: Contribuições da Afipea-Sindical para reflexão e desenvolvimento Institucional. Brasília: Afipea, 2020.

MACHADO LIMA JUNIOR, H. Participação 
Democrática e Justiça Distributiva para o Desenvolvimento: a definição ideológica do neodesenvolvimentismo pela DIEST/IPEA entre 2010 e 2012 e sua tradução em políticas públicas. Ponto de Vista, n. 6, Dezembro, 2015. Rio de Janeiro.

MANSOR DE MATTOS, F. A.. "O debate sobre distribuição de renda ao longo do processo de desenolvimento econômico do Brasil". Revista da ABET, v. 16, n. 1, Jan-Jun. 2017.

MOTA, L. A. Os movimentos sociais na crise financeira global: questões e polêmicas. Unisinos, v. 49, n. 3, pp. 288-296, Setembro/ Dezembro 2013.

MOUNK, Y. The People vs. Democracy: Why our freedom is in danger. Cambridge: Harvard University Press, 2018.

OFFE, C. Trabalho: uma categoria chave da sociologia?. In: Offe, C. (org.) Trabalho e sociedade: problemas estruturais e perspectivas para o futuro da Sociedade do trabalho. Rio de Janeiro: Tempo Brasileiro, 1989

PIKETTY, T. Capital in the Twenty-First Century. Cambridge: Belknap Press of Harvard University, 2014.
ROBINSON, W. \& BARRERA, M. Global Capitalism and twennty-first century fascism: a US case study. Race and Class. Institute of Race Relations, v. 53m n. 3, pp. 4-29, 2012.

SINTOMER, Y; HERZBERG, C. \& RÖCKE, A. Modelos Transnacionais de Participação Cidadã: o Caso do Orçamento Participativo. Sociologias, Porto Alegre, ano 14, n. 30, maio-ago, 2012, pp. 70-116.

SGI. Policy Performance and Governance Capacities in the OECD and EU Sustainable Governance Indicators 2018.

SOUZA E SILVA, C. A. Reforma Política e Desenvolvimento em Hélio Jaguaribe. CS Online - Revista Eletrônica de Ciências Sociais. Novembro, 2007.

SPENCER, H. Social Statistics. New York Robert Schalkenbach Foundation, 2020.

WOLF, M. Why rigged capitalism is damaging liberal democracy. Financial Times. September, 2019. 